\title{
Design of brain-computer interface-based classification model for mining mental state of COVID-19 afflicted mariner's
}

\author{
Manik Sharma
}

Department of CSA, DAV University Jalandhar, India

The corona-virus (COVID-19) has tremendously crippled the whole world and eventually swayed the lifestyle, behaviour, and cognitive health of the people [1]. To restrict the dissemination of COVID-19, most of the countries had imposed a partial or complete lockdown. However, nowadays, most of the countries have started the unlocked-down phase. Most of the services have been restarted and the individuals are free to move as per the government advisories and the precautionary measures.

The complete world trade business and the global economy are significantly based upon the maritime industry and the seafarers. Shipping is recognised as a pillar of globalisation and foreign exchange. More than 2 million seafarers are working across the globe and support to complete all the sea transactions [2]. Like other professionals, the extreme working conditions, job responsibility, erratic schedule, chemical hazards, salvage diving, asbestosis and psychosocial factors are inducing a high degree of stress (psychological disorders) among seafarers and mariners. Unfortunately, the effects of COVID-19 have also been seen on shipping and marine industry. The study has shown that during this pandemic (COVID-19) 50\% (of the sample study) of the mariners did not feel safe and more than 50\% employees were not satisfied with the precautionary measures taken to deal with this global epidemic [3]. All these concerns are devastating their mental as well as physical state. No doubt, the people have started their work; however, still, there is a great fear of having a COVID-19 infection.

The mental state of the individuals has been greatly affected and consequently, most of the persons are suffering from different psychiatric and neuropsychiatric disorders. A single COVID-19 victim can create chaos in a ship. This chaos can trigger stress as well as other human psychological disorders among different persons travelling through the ship. Therefore, to ensure the healthy state of the mariners, there is a need to examine the mental state (mind alertness) along with their body temperature (thermal checking). The mental state of the individuals can be easily accessed using electroencephalography (EEG) signals [4]. A brain-sense device can be used to capture the frequency of the brainwave signals and consequently, the mental state of a seafarer or mariner can be reflected. The key contribution of this research work is to present a framework (Fig. 1) for the diagnosis of the mental state of the mariners during the traumatic period of COVID-19.

The model is framed using an amalgamation of brain-computer interface $(\mathrm{BCl})$ and soft computing techniques. $\mathrm{BCl}$ is an emerging research area in the domain of human-computer interaction. $\mathrm{BCl}$ is related to the communication of thoughts (originated in the brain) without using any muscular control [5]. In $\mathrm{BCl}$ systems, the brain activities are recorded in the form of the brainwaves and are transmitted to the computing machine for recording and pattern recognition. Some of the major applications of the $\mathrm{BCl}$ are prosthetic control (home appliances and wheelchair control), operator monitoring, forensics (lie detection, trust assessment), entertainment (mood assessment, thought control, response detection), healthcare (drowsiness detection, neuro-rehabilitation), and neuro-market [6]. In healthcare, $\mathrm{BCl}$ has been effectively employed in different areas ranging from prevention to rehabilitation. The effective outcomes of $\mathrm{BCl}$ in prevention (smoking, alcoholism), prognosis (neurological and psychiatric disorders), and rehabilitation (brain, disability and psychiatric disorders) have also been witnessed [4]. Here, an artificial intelligent $\mathrm{BCl}$ has been proposed to generate and record the mental state (brain-waves) of the seafarers. The brain-sense devices are used for $\mathrm{BCl}$. Some of the important characteristics of the brain-sense devices are [7]: 


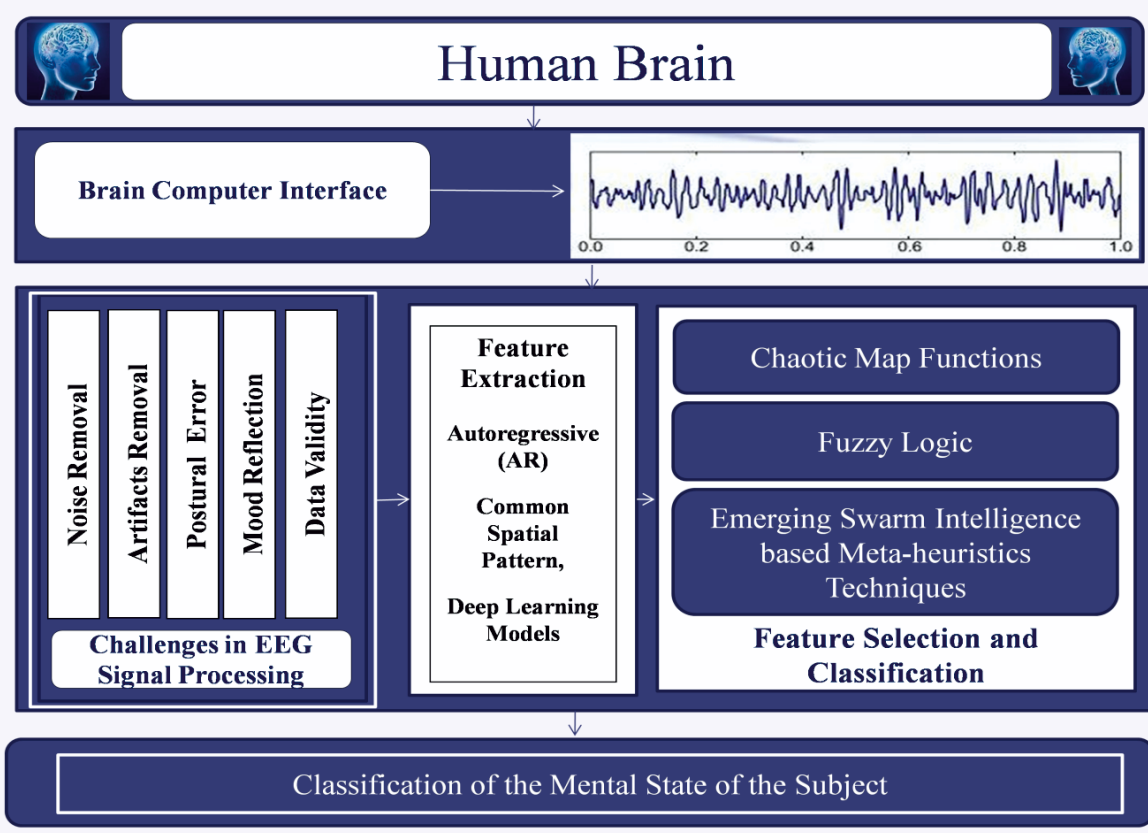

Figure 1. Diagnosis of mental states of humans

- it can be used to get a RAW EEG at $512 \mathrm{MHz}$ with an operating voltage of 2.97-3.63 $\mathrm{V}$ along with the frequency range $3-100 \mathrm{~Hz}$;

- the attention level and the different EEG frequency bands can also be detected using this $\mathrm{BCl}$ device;

- the level of human stress can be diagnosed;

- the efficiency in performing a particular task can be monitored;

- the brainwave signal captured using brain-sense can be further explored for diagnosis of different human neuropsychiatric disorders.

The data will be then preprocessed to remove different kinds of noise generated through artefacts, postural, and mood of the subject. Different feature extraction (time/frequency domain, CSP, DL models) and feature selection techniques (Swarm Intelligence [Whale-Optimization, Grey-Wolf Optimizer, Dragonfly Algorithm, Harris-Hawks Algorithm, Ant-Colony Optimization, Particle-Swarm Optimization, etc.], fuzzy logic, and chaotic map) can be used to extract discriminative information and for precise diagnosis of different neuropsychiatric disorders. The proposed $\mathrm{BCl}$ assists to classify the state (sleepy, drowsiness, relaxed, active, highly active and conscious) of the seafarers. The proposed system is able to solve the multi-classification diagnostic problem.

Moreover, for mitigation of the psychiatric and neuropsychiatric disorders, there is a tremendous need to design and implement a mental healthcare policy that focuses on providing psychological intervention, mobile and online mental health services to the COVID-19 afflicted seafarers. The delay in this health policy can drastically magnify the stress, anxiety, depression and other psychological disorders [8]. Initially, the use of digital technologies may bridge the gap between social distancing. Secondly, a comprehensive therapeutic technique (psychotherapy) would be used to understand and rectify the behaviours, thoughts, and emotions of COVID-19 afflicted individuals. The use of in place cognitive and behaviour therapies may assist to transform the mental state and behaviour of these victims. The psychological interventions strengthen the morale of persons and could be effective in mitigating the psychological impacts of this pandemic. The functioning of the immune system can also be significantly optimised with psychiatric therapies (cognitive and behaviour).

The use of mobile health ( $m$-health) services such as calls (audio, video), apps (WhatsApp, zoom, WeChat), messages (text, audio, picture, video) would be an important way to mental stepped care. Different $m$-health services can be used to provide cognitive and behaviour therapies to quarantined individuals so that they can well cope with this global epidemic. The early and timely mobile (remote) psychiatric intervention during this corona storm can even mitigate the risk and mortality rate of suicides [9]. Additionally, there is a dire need to design and implement free web-based mental health services (like www.betterhelp. com, www.moodgym.com.au, www.beyondblue.org.au, etc.) for effective management of the different psychiatric conditions (stress, anxiety, depression, suicide, anger and sleep disorders) of the seafarers. 
In light of the aforementioned findings, the proposed $\mathrm{BCl}$ based classification model will help mariner to diagnose their mental state so that if require the remote mental health services can be provided to alleviate the risk of any psychiatric and neuropsychiatric disorders.

\section{REFERENCES}

1. Sharma S, Sharma M, Singh G. A chaotic and stressed environment for 2019-nCoV suspected, infected and other people in India: Fear of mass destruction and causality. Asian J Psychiatr. 2020; 51: 102049, doi: 10.1016/j.ajp.2020.102049, indexed in Pubmed: 32278890.

2. Doumbia-Henry C. Shipping and COVID-19: protecting seafarers as frontline workers. WMU J Maritime Affairs. 2020; 19(3): 279-293, doi: 10.1007/s13437-020-00217-9.

3. Pesel G, Canals ML, Sandrin M, et al. Wellbeing of a selection of seafarers in Eastern Adriatic Sea during the COVID-19 pandemic 2020. Int Marit Health. 2020; 71(3): 184-190, doi: 10.5603/ IMH.2020.0033, indexed in Pubmed: 33001430.

4. Lin $\mathrm{CT}$, Chuang $\mathrm{CH}$, Cao Z, et al. Forehead EEG in support of future feasible personal healthcare solutions: sleep management, heada- che prevention, and depression treatment. IEEE Access. 2017; 5: 10612-10621, doi: 10.1109/access.2017.2675884.

5. Padfield N, Zabalza J, Zhao H, et al. EEG-Based Brain-Computer Interfaces Using Motor-Imagery: Techniques and Challenges. Sensors (Basel). 2019; 19(6): 1423, doi: 10.3390/s19061423, indexed in Pubmed: 30909489.

6. Abdulkader S, Atia A, Mostafa MS. Brain computer interfacing: Applications and challenges. Egyptian Info J. 2015; 16(2): 213-230, doi: 10.1016/j.eij.2015.06.002.

7. Avudaiammal R, Mystica K, Balaji A, et al. Brain Sense Controlled Wireless Robot: Interfacing Neurosky Brainsense to a Wheelchair Prototype. 2020 Third International Conference on Smart Systems and Inventive Technology (ICSSIT). 2020, doi: 10.1109/ icssit48917.2020.9214100.

8. Duan Li, Zhu G. Psychological interventions for people affected by the COVID-19 epidemic. Lancet Psychiatry. 2020; 7(4): 300-302, doi: 10.1016/S2215-0366(20)30073-0, indexed in Pubmed: 32085840.

9. Reger MA, Stanley IH, Joiner TE. Suicide Mortality and Coronavirus Disease 2019-A Perfect Storm? JAMA Psychiatry. 2020 [Epub ahead of print], doi: 10.1001/jamapsychiatry.2020.1060, indexed in Pubmed: 32275300. 